\title{
Correction to: Benefit-Risk Assessment of Obesity Drugs: Focus on Glucagon-like Peptide-1 Receptor Agonists
}

\author{
Rasmus M. Christensen ${ }^{1}$ (D) . Christian R. Juhl ${ }^{1}$ (1) $\cdot$ Signe S. Torekov ${ }^{1}$ (1)
}

Published online: 30 April 2019

c) Springer Nature Switzerland AG 2019

\section{Correction to: Drug Safety}

https://doi.org/10.1007/s40264-019-00812-7

In the original publication of this article, the following correction should be noted in Table 1.

The drug "Orlistat" was incorrectly changed to "Gastrointestinal lipase inhibitor". Indeed, the "Pancreas lipase inhibitor" in the column "Primary mechanism of action" should have been replaced with "Gastrointestinal lipase inhibitor".

The original article has been corrected.

The original article can be found online at https://doi.org/10.1007/ s40264-019-00812-7.

Signe S. Torekov torekov@sund.ku.dk

1 Department of Biomedical Sciences and Novo Nordisk Foundation Center for Basic Metabolic Research, University of Copenhagen, Blegdamsvej 3B, 2200 Copenhagen N, Denmark 